\title{
PEMANFAATAN PUPUK ORGANIK CAIR TANDAN KELAPA UNTUK PERTUMBUHAN BIBIT PINANG (ARECA CATECHU L.) DI TANAH GAMBUT
}

\author{
Yoyon Riono ${ }^{1}$, Mulono Apriyanto², \\ ${ }^{1}$ Jurusan Agroteknologi, Fakultas Pertanian, Universitas Islam Indragiri Tembilahan \\ 2Jurusan Teknologi Pangan, Fakultas Pertanian, Universitas Islam Indragiri, Tembilahan \\ Email: yoyonriono353@gmail.com (korespondensi)
}

\begin{abstract}
This study aims to determine the concentration of liquid organic fertilizer of coconut bunches for the growth of areca nut seedlings. This research was conducted in the experimental field of the agricultural faculty of Indragiri Islamic University from July to November 2020. This research was conducted in the form of an experiment using a non-factorial completely randomized design consisting of 5 levels and 3 replications. Coconut bunches liquid organic fertilizer consists of $0,50,70,90,110 \mathrm{ml}$. The data were statistically analyzed and further examined using the HSD test at the 5\% level. The results showed that increasing the dose of liquid organic fertilizer of coconut bunches increased the growth of seedling height, dry weight and root crown ratio, increased the number of leaves, the increase in stem circumference and the widest leaf area. The dose of liquid organic fertilizer for coconut bunches is $750 \mathrm{ml}$. increased the increase in seedling height, dry weight
\end{abstract}

Keywords: Areca nut, Coconut Bunch POC, Peat

\begin{abstract}
Abstrak
Penelitian ini bertujuan untuk mengetahui Konsentrasi pemberian pupuk organik cair tandan kelapa untuk pertumbuhan bibit pinang. Penelitian ini dilakukan di lahan percobaan fakultas pertanian Universitas Islam Indragiri dari Juli hingga November 2020. Penelitian ini dilakukan dalam bentuk percobaan menggunakan rancangan acak lengkap non faktorial yang terdiri dari 5 taraf dan 3 ulangan. Pupuk organik cair tandan kelapa terdiri dari 0, 50, 70, 90, 110 ml. Data telah dianalisis scara statistik dan diperiksa lebih lanjut dengan menggunakan uji HSD pada taraf 5\%. Hasil penelitian menunjukan bahwa peningkatan dosis pupuk organik cair tandan kelapa meningkatkan pertambahan tinggi bibit, berat kering dan rasio tajuk akar, meningkatkan pertambahan jumlah daun, pertambahan lingkar batang dan luas daun terluas. Dosis pupuk organik cair tandan kelapa $750 \mathrm{ml}$. meningkatkan pertambahan tinggi bibit, berat kering
\end{abstract}

Kata kunci: Pinang, POC Tandan Kelapa, Gambut

\section{PENDAhuluan}

Pinang (Areca catechu L.) merupakan salah satu tanaman tahunan yang sangat dikenal oleh masyarakat karena secara alami penyebarannya cukup luas di berbagai daerah. Beberapa jenis pinang yang dikenal di Indonesia, di antaranya pinang biru, pinang hutan, pinang Irian, pinang kelapa, pinang sirih dan pinang merah (Lutony dan Rahmayati 1994). Tanaman pinang adalah salah satu jenis palma, yang ditanam terutama untuk dimanfaatkan bijinya, di dunia barat dikenal sebagai betel nut. Biji pinang memiliki banyak kegunaan antara lain bermanfaat sebagai bahan industri farmasi, kosmetika, bahan pewarna pada industri tekstil dan juga untuk dikonsumsi dikenal sebagai salah satu campuran saat orang makan sirih, selain gambir dan kapur (Syukur dan Hernani, 2001)

Salah satu komuditi ekspor hasil perkebunan Indonesia adalah buah pinang. Buah pinang banyak dijumpai di berbagai wilayah di Indonesia karena tumbuhan ini dapat tumbuh di wilayah iklim tropis. Setiap tahun hasil produksi perkebunan buah pinang mengalami kenaikan. Menurut Badan Pusat Statistik (2017) buah pinang mengalami peningkatan produksi dari tahun 
2012 hingga 2015. Kenaikan tiap tahunnya adalah 1,86 \% pada tahun 2013, 8,9 \% pada tahun 2014 dan $0,21 \%$ pada tahun 2015. Peningkatan hasil produksi buah pinang dimanfaatkan oleh masyarakat sebagai peluang bisnis, salah satunya adalah melalui kegiatan ekspor

Tanaman pinang menjadi komoditi perdagangan ekspor dari Indonesia yang diarahkan ke negaranegara Asia Selatan seperti India, Pakistan, Bangladesh, atau Nepal. Negara-negara pengekspor pinang utama adalah Indonesia, Thailand, Malaysia, Singapura, dan Myanmar (Kementrian Pertanian, 2013). Sentra tanaman pinang di Indonesia adalah di Pulau Sumatera dan Nusa Tenggara Timur. Penyebarannya meliputi Aceh, Riau, Sumatera Utara, dan Kalimantan Barat (Balai Penelitian Tanaman Palma, 2012). Mengingat potensi buah pinang sebagai komuditi ekspor maka membuka peluang pengembangan pinang di wilayah Indonesia lainnya. Salah satu upaya untuk mendukung pengembangan pinang yaitu dengan menjamin ketersediaan bibit, sehingga perlu dilakukan kegiatan pembibitan. Pembibitan merupakan salah satu usaha yang dilakukan untuk menghasilkan bibit yang bermutu dan berkualitas serta siap untuk ditanam (Lubis, 2008).

Usaha untuk menjamin keberhasilan pengembangan pinang khususnya pembibitan pinang, perlu adanya kegiatan pemeliharaan yang memadai di pembibitan. Pemupukan merupakan kegiatan pemeliharaan. Pemupukan yaitu salah satu cara untuk memperbaiki tingkat kesuburan tanah dan meningkatkan pertumbuhan dan produksi tanaman (Nyakpa et al., 1998). Pemupukan dapat dilakukan dengan pemberian pupuk organik dan anorganik. Penggunaan pupuk organik merupakan alternatif yang baik untuk meningkatkan kesuburan tanah dan ramah lingkungan. Pupuk organik yang digunakan salah satunya yaitu pupuk organik cair tandan kelapa, dimana bahannya dapat digunakan dari limbah tandan kelapa yang tidak lagi digunakan oelh petani Menurut Pranata (2004), pupuk organik merupakan pupuk yang berasal dari makhluk hidup yang telah mati, juga dapat berasal dari sisa tumbuhan ataupun dari limbah rumah tangga dll

Pengelolaan lahan gambut untuk keperluan manusia memiliki kendala yang cukup serius. Lahan gambut yang dimanfaatkan untuk pertanian tanaman pangan dan perkebunan, apabila tidak cermat dan tidak sesuai dengan karakteristiknya dapat merusak keseimbangan ekologis wilayah (Tim Sintesis Kebijakan, 2008). Lahan gambut punya peran besar untuk lingkungan karena dapat mencegah larinya gas rumah kaca (CO2) yang menyebabkan perubahan iklim, habitat basah lahan gambut dapat menyerap sebagian besar karbon dan menyimpannya (Najiyati, 2005). Selain itu, lahan gambut juga punya fungsi hidrologi yaitu sebagai cadangan air, produksi yaitu sebagai cadangan kayu, dan ekologi yaitu sebagai habitat flora dan fauna, yang semua fungsi tersebut sangat vital bagi kelangsungan hidup manusia (Masganti, 2013).

Lahan gambut dikenal sebagai lahan yang rapuh atau rentan dengan perubahan karakteristik yang tidak menguntungkan. Oleh karena itu perlu pengelolaan yang khas agar tidak terjadi perubahan karakteristik yang menyebabkan produktivitas lahan menurun, apalagi menjadi tidak produktif. Terdapat beberapa pengertian tentang lahan gambut terdegradasi. Pengertian-pengertian ini terkait dengan kondisi karbon di atas permukaan tanah. Lahan gambut dianggap terdegradasi jika mengandung karbon kurang dari 35 t.ha-1 (Rieley et al. 2008; Bapenas 2009). Hal ini didasarkan atas pertimbangan bahwa kadar karbon dalam lahan gambut telah mengalami penurunan yang signifikan baik karena kebakaran, maupun akibat subsidensi yang cepat. Kedua peristiwa tersebut memacu emisi gas rumah kaca (GRK), termasuk karbon (Agus et al. 2012).

Berdasarkan uraian di atas penulis telah melakukan penelitian dengan judul "Pemanfaatan Pupuk Organik Cair Kulit Buah Pisang untuk Pertumbuhan Bibit Pinang (Areca catechu L.)"

Penelitian ini bertujuan untuk mengetahui pengaruh pemberian pupuk organik cair kulit buah pisang serta mendapatkan dosis terbaik untuk pertumbuhan bibit pinang.

\section{TINJAUAN PUSTAKA}

\subsection{Tinjauan Umum dan Morfologi Tanaman Pinang}

Pinang sirih (Areca cathecu L.) merupakan tanaman yang sekeluarga dengan kelapa.Salah satu jenis tumbuhan monokotil ini tergolong ke dalam jenis palem-paleman. Secara detail pinang diklasifikasikan sebagai berikut: Kingdom: Plantae, Devisi: Spermatophyta, Subdivisi: Angiospermae, Kelas: Monocotyledonae, Ordo: Areales, Famili: Arecaceae/Palmae, Genus: Areca, Spesies: Areca catechu L. (Sihombing, 2000). 
Tanaman pinang adalah tanaman monokotil. Akar tanaman pinang tergolong akar serabut. Akar tanaman pinang sangat mirip dengan akar kelapa, karena masih satu family yaitu palmae (Miftahorrachman, 2015). Pinang merupakan tanaman soliter (tumbuh secara individual).Berbatang lurus dan agak licin dengan tinggi dapat mencapai 25 meter dan diameter batang atau jarak antar ruas batang sekitar $15 \mathrm{~cm}$. garis lingkaran pada batang tampak jelas (Sihombing, 2000). Jumlah daun pinang bervariasi antara 7-10 helai. Daun pinang berbentuk menyirip mejemuk dengan panjang antara $1-1,8 \mathrm{~m}$, memiliki anak daun (leaflet) berjumlah antara 30-50 pinak daun (Miftahorrachman, 2015).

Bunga pinang berumah satu, bunga jantan dan bunga betina berada dalam satu rangkaian bunga (inflorescence). Bunga betina terletak pada bagian dasar dari tangkai rangkaian bunga (spikelet), sedangkan bunga jantan ukurannya lebih kecil, jumlahnya banyak dan terletak menyebar meluas dari bagian luar sampai bagian ujung tangkai rangkaian bunga. Bunga jantan maupun bunga betina memiliki 6 petal, tetapi tidak memiliki tangkai bunga dan berwarna putih susu. Bunga jantan memiliki 6 benang sari (stamen). Bunga betina berukuran panjang 1,3-2,0 cm lebih besar dari bunga jantan, memiliki 6 benang sari yang steril dan 3 indung telur (ovary) yang memiliki stigma berbentuk segitiga (Miftahorrachman, 2015). Buah pinang berbentuk bulat telur mirip telur ayam dengan ukuran sekitar 3,5-7 cm. buah pinang berwarna hijau saat muda dan berubah merah jingga atau merah kekuningan saat masak atau tua (Sihombing, 2000).

\subsection{Syarat Tumbuh Tanaman Pinang}

Tanaman pinang dapat tumbuh pada berbagai jenis tanah, tapi yang paling sesuai adalah jenis tanah berliat (clay loam). Selain itu yang perlu diperhatikan adalah tanah harus beraerasi baik, solum tanah dalam dan tidak terdapat lapisan cadas (Miftahorrachman, 2015). Van Steenis (2003) mengatakan tanaman pinang dapat tumbuh pada daerah-daerah dengan ketinggian mulai dari 1 meter sampai dengan 1.400 meter di atas permukaan laut. Tanaman pinang membutuhkan kelembapan tanah yang cukup dan curah hujan yang tinggi sepanjang tahun berkisar 1500-5000 $\mathrm{mm}$ dengan hari hujan berkisar 100-150 hari.

Cahaya matahari sangat berpengaruh dalam pertumbuhan tanaman pinang.
Kebutuhan cahaya matahari yang ideal adalah 6-8 jam per hari. Beberapa pengaruh cahaya matahari terhadap pertumbuhan tanaman pinang, antara lain: 1.) jarak antar ruas batang (nodus) lebih pendek; 2.) pertumbuhan tanaman tidak cepat tinggi; 3.) fisik tanaman lebih kuat dan 4.) persentase bunga betina menjadi lebih besar (Miftahorrachman, 2015).

\subsection{Kandungan Tanaman Pinang}

Biji Pinang mengandung alkaloid yang bekerja kolinergik, seperti arecoline (C8H13NO2), arecolidine, arecain, guvacoline, guvacine.Selain itu, mengandung tanin (areca red), lemak (palmitic, oleic, linoleic, palmitoleic, stearic, myristic acid), saponin, steroid, asam amino, choline, flavonoid, dan catechin. Biji segar mengandung lebih banyak alkaloid dibandingkan biji yang telah diproses (Dalimartha, 2009). Satriadi (2011) melaporkan kadar tanin dalam biji pinang berkisar antara $17-20 \%$.

\subsection{Manfaat Tanaman Pinang}

Tumbuhan pinang telah lama dikenal dan hampir semua bagian tumbuhan dapat dimanfaatkan. Biji pinang berkhasiat sebagai antielmintik, penenang, mengobati luka, memperbaiki pencernaan, meluruhkan dahak dan malaria. Sabut buah pinang dapat digunakan untuk mengatasi gangguan pencernaan (dispepsia), sulit buang air besar (sembelit), edema dan beri-beri karena urin sedikit (Delimartha, 2009). Sedangkan Setriadi (2011) melaporkan bahwa air rebusan dari biji pinang digunakan untuk mengatasi penyakit haid dengan darah berlebihan, hidung berdarah (mimisan), koreng, borok, bisul, eksim, kudis, difteri, cacingan (kremi, gelang, pita, tambang) dan disentri. Selain itu tanaman pinang juga digunakan untuk mengatasi bengkak karena retensi cairan (edema), rasa penuh di dada, luka, batuk berdahak, diare, terlambat haid, keputihan, beri-beri, malaria, memperkecil pupil mata.

Biji dan kulit bagian dalam dapat juga digunakan untuk menguatkan gigi goyah, bersama-sama dengan sirih. Air rendaman biji pinang muda digunakan untuk obat sakit mata. Umbut (bagian tengah/dalam) pinang muda digunakan untuk mengobati patah tulang, dan sakit pinggang (salah urat). Selain itu umbut juga dapat dimakan sebagai sayuran. Daun pinang berguna untuk mengatasi masalah tidak nafsu makan dan sakit pinggang (Satriadi, 2011).

\section{METODOLOGI PENELITIAN}


Penelitian ini telah dilaksanakan di kebun percobaan Fakultas Pertanian Universitas Islam Indragiri, Jalan Propinsi Parit 1 Kelurahan Tembilahan Hulu, Kecamatan Tembilahan Hulu, Tembilahan. Penelitian ini dilaksanakan selama tiga bulan mulai dari bulan Juli sampai bulan November 2020.

Bahan yang digunakan dalam penelitian ini adalah bibit pinang Jenis pinang yang diperoleh dari petani di desa Pulau Palas, pupuk organik cair tandan kelapa, tanah gambut, air, insektisida Decis 25 EC dan fungisida Dithane M-45, EM4, molases, polynet, amplop kertas padi, pupuk NPK mutiara 16:16:16.

Alat yang digunakan dalam penelitian ini adalah cangkul, parang, ayakan, ember, gembor, timbangan digital, cutter, mistar, gelas ukur, oven, handsprayer, meteran, polybag ukuran $30 \mathrm{~cm} \times 35 \mathrm{~cm}$, alat tulis dan kamera

Penelitian ini dilakukan secara eksperimen dengan menggunakan rancangan acak lengkap (RAL) non factorial terdiri dari 5 taraf dosis POC kulit buah pisang dengan 3 ulangan. 5 taraf konsentrasi POC tandan kelapa yaitu: POCO $(0 \mathrm{ml})$, POC1 $(50 \mathrm{ml})$, POC2 $(70 \mathrm{ml})$, POC3 $(90 \mathrm{ml})$, POC4 (110).

Dari perlakuan tersebut diperoleh 15 satuan percobaan, untuk masing-masing satuan percobaan terdiri dari 3 tanaman sehingga total populasi 45 tanaman.

\section{HASIL DAN PEMBAHASAN}

\subsection{Pertambahan Tinggi Bibit (cm)}

Hasil analisis sidik ragam menunjukan bahwa pemberian konsentrasi pupuk organik cair tandan kelapa berpengaruh nyata terhadap tinggi tanaman bibit pinang di media gambut. Hasil uji lanjut dengan HSD pada taraf $5 \%$ dapat dilihat pada table dibawah ini;

Tabel 1 Pemanfaatan Pupuk Organik Cair Tandan Kelapa untuk pertumbuhan bibit pinang (Areca catechu L) di media gambut

\begin{tabular}{|c|c|c|c|}
\hline \multicolumn{3}{|c|}{ Konsentrasi POC Tandan Kelapa } & $\begin{array}{l}\text { Tinggi } \\
\text { Bibit }(\mathrm{cm})\end{array}$ \\
\hline \multicolumn{3}{|c|}{$0 \mathrm{ml}$ konsentrasi POC tandan kelapa } & $18 \mathrm{~d}$ \\
\hline $\begin{array}{l}50 \mathrm{ml} / 500 \mathrm{ml} \\
\text { tandan kelapa }\end{array}$ & konsentrasi & POC & $20 \mathrm{c}$ \\
\hline $\begin{array}{l}70 \mathrm{ml} / 500 \mathrm{ml} \\
\text { tandan kelapa }\end{array}$ & konsentrasi & POC & $22 b$ \\
\hline $\begin{array}{l}90 \mathrm{ml} / 500 \mathrm{ml} \\
\text { tandan kelapa }\end{array}$ & konsentrasi & POC & $24 a$ \\
\hline $\begin{array}{l}110 \mathrm{ml} / 500 \mathrm{ml} \\
\text { tandan kelapa }\end{array}$ & konsentrasi & POC & $22 \mathrm{~b}$ \\
\hline
\end{tabular}

Angka-angka yang di ikuti oleh huruf yang berbeda pada kolom yang sama menunjukan perbedaan yang nyata pada taraf terkecil $5 \%$ menurut uji HSD
Tabel 1 memperlihatkan bahwa pemberian pupuk organik cair tandan kelapa dengan konsentrasi $90 \mathrm{ml} / 500 \mathrm{ml}$ menunjukan tinggi bibit yang tertinggi yaitu $24 \mathrm{~cm}$ dan berbeda nyata dengan pemberian dosis $0,50,70$ dan $110 \mathrm{ml}$. POC tandan kelapa. Hal ini dikarenakan pada pemberian dosis $90 \mathrm{ml}$ medium unsur hara yang berasal dari POC tandan kelapa telah mencukupi sehingga mampu memberikan respon yang baik terhadap pertambahan tinggi bibit pinang. Novizan (2002) menyatakan bahwa pertumbuhan tanaman optimal apabila unsur hara yang dibutuhkan tersedia dalam jumlah yang cukup bagi tanaman.

Pemberian POC tandan kelapa dengan konsentrasi $90 \mathrm{ml}$ dapat menambah bahan organik dalam tanah dan dapat membantu aktivitas mikroorganisme di dalam tanah. Hal ini dikarenakan pupuk organik dapat memperbaiki sifat fisik, biologi dan kimia tanah menjadi lebih baik, dimana bahan organik di dalam tanah merupakan sumber makanan, energi dan karbon bagi mikroorganisme. Mikroorganisme berperan dalam perombakkan bahan organik di dalam tanah, sehingga struktur tanah menjadi lebih baik dan unsur hara tersedia terutama unsur $\mathrm{N}, \mathrm{P}$ dan $\mathrm{K}$ dapat diserap tanaman dengan baik untuk pertumbuhan tanaman. Menurut Lingga (1997), bahan organik mampu memperbaiki struktur tanah dengan membentuk butiran tanah yang lebih besar oleh senyawa perekat yang dihasilkan oleh mikroorganisme yang terdapat pada bahan organik. Butiran-butiran yang lebih besar akan memperbaiki permeabilitas dan agregat tanah sehingga daya serap serta daya ikat tanah terhadap air akan meningkat. Kondisi ini mampu mendukung pertumbuhan bibit yaitu tinggi bibit.

$$
\text { Hasnadi dan Saleh }
$$

menyatakan bahwa bahan organik dapat memperbaiki sifat fisika tanah, menggiatkan mikroorganisme, meningkatkan jumlah air dan memberikan pertumbuhan akar tanaman menjadi lebih baik. Menurut Hakim et al (1986) bahan organik adalah bahan pemantapan agregat tanah yang merupakan sumber hara tanaman, sumber energi dari sebagian besar organisme tanah, sehingga menyebabkan perkembangan akar menjadi lebih baik dan dapat meningkatkan absorsi unsur hara terutama Nitrogen oleh akar. Menurut Sutejo dan Kartasapoetra (1998) bahwa pertumbuhan vegetatif tanaman diperlukan unsur hara $\mathrm{N}$ yang merupakan bagian dari protoplasma dan inti sel. Sebagai bagian dari inti sel, unsur tersebut sangat penting dalam pembelahan sel dan perkembangan jaringan jaringan maristem. 
Unsur P dibutuhkan tanaman diantaranya untuk pembentukan adenosin trifosfat (ATP). Adenosin trifosfat adalah energi yang dibutuhkan tanaman dalam setiap aktivitas sel yang meliputi pembelahan sel, pembesaran sel dan pemanjangan sel di titik tumbuh apikal sehingga ketersediaan ATP yang tinggi mampu meningkatkan pertumbuhan tinggi bibit pinang. Gardner et al. (1991) menyatakan bahwa pertumbuhan tinggi tanaman terjadi karena pembelahan sel dan peningkatan jumlah sel yang membutuhkan energi dalam bentuk ATP. Selain unsur N dan $P$ unsur $K$ juga dibutuhkan dalam meningkatkan pertumbuhan tinggi tanaman. Unsur $\mathrm{K}$ berperan diantaranya sebagai aktivator enzim dalam reaksi fotosintesis, sehingga peningkatan unsur $\mathrm{K}$ akan meningkatkan laju fotosintesis dan fotosintat yang dihasilkan serta dimanfaatkan untuk pertumbuhan tinggi bibit. Salisbury dan Ross (1995) menyatakan bahwa peranan utama unsur $K$ pada tanaman adalah sebagai aktivator berbagai enzim diantaranya untuk fotosintesis dan respirasi.

\subsection{Jumlah daun (helai)}

Hasil analisis sidik ragam menunjukan bahwa pemberian konsentrasi pupuk organik cair tandan kelapa tidak berpengaruh nyata terhadap jumlah daun bibit pinang di media gambut. Hasil uji lanjut dengan HSD pada taraf $5 \%$ dapat dilihat pada table dibawah ini;

Tabel 2 Pemanfaatan Pupuk Organik Cair Tandan Kelapa untuk pertumbuhan bibit pinang (Areca catechu L) di media gambut

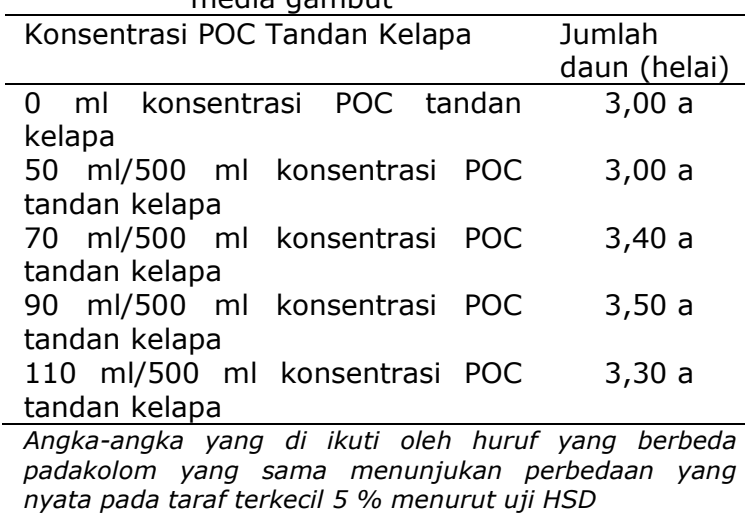

Tabel 2 memperlihatkan bahwa pemberian POC tandan kelapa pada konsentrasi 0-110 ml menunjukkan jumlah daun bibit pinang yang tidak berbeda nyata. Hal ini diduga pemberian POC tandan kelapa dengan dosis yang berbeda belum mampu meningkat pertambahan jumlah daun pada bibit pinang sehingga jumlah daun bibit pinang relatif seragam pada setiap perlakuan namun kalau dilihat secara fisiologis dari warna daun sangat baik yang terlihat sangat hijau.

Menurut Sumiati dan Gunawan (2007) pembentukan umbi bawang merah berasal dari lapisan daun yang membesar dan menyatu. Pembetukan lapisan yang membesar ini terbentuk dari mekanisme kerja $\mathrm{N}$. unsur hara $\mathrm{N}$ menyebabkan proses kimia yang menghasilkan asam nukleat, yang berperan dalam inti sel dalam proses pembelahan sel, sehingga lapisan -lapisan daun dapat terbentuk dengan baik dan selanjutnya berkembang menjadi umbi bawang merah. Pembelahan dan pembesaran sel menjadi terhambat bila kekurangan hara $\mathrm{N}$ sehingga umbi berkurang.

Menurut Harjadi (2002), tanaman dapat tumbuh optimal jika unsur hara tersedia, pertumbuhan tanaman tergantung dari unsur hara yang diperoleh dari dalam tanah serta dipengaruhi oleh penambahan unsur hara dari pemberian berbagai pupuk. Unsur hara yang berperan besar dalam pertumbuhan dan perkembangan daun yaitu nitrogen. Lakitan (2010) menyatakan bahwa salah satu unsur hara yang berpengaruh terhadap pertumbuhan dan perkembangan daun adalah unsur $N$. nitrogen merupakan hara esensial yang berperan dalam pertumbuhan vegetatif diantaranya untuk pembentukan daun.

\subsection{Lingkar Batang (cm)}

Hasil analisis sidik ragam menunjukan bahwa pemberian konsentrasi pupuk organik cair tandan kelapa tidak berpengaruh nyata terhadap lingkar batang bibit pinang di media gambut. Hasil uji lanjut dengan HSD pada taraf $5 \%$ dapat dilihat pada table dibawah ini;

Tabel 3 Pemanfaatan Pupuk Organik Cair Tandan Kelapa untuk pertumbuhan bibit pinang (Areca catechu L) di media gambut

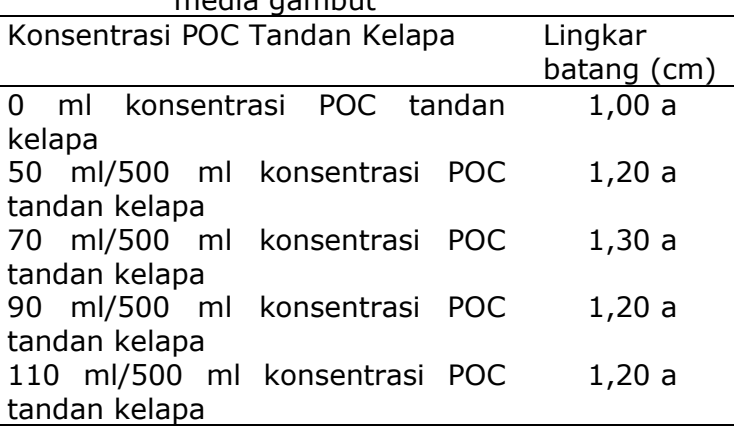


Angka-angka yang di ikuti oleh huruf yang berbeda pada kolom yang sama menunjukan perbedaan yang nyata pada taraf terkecil $5 \%$ menurut uji HSD

Tabel 3 memperlihatkan bahwa pemberian POC tandan kelapa dengan berbagai konsentrasi menunjukkan lingkar batang bibit pinang tidak berbeda nyata. Hal ini dikarenakan kandungan unsur hara yang terdapat pada POC kulit buah pisang berdasarkan hasil analisis masih tergolong rendah, selain itu medium tanam yang digunakan dalam penelitian adalah jenis tanah gambut dimana tanah tersebut memiliki kandungan unsur hara rendah dan $\mathrm{pH}$ masam sehingga menyebabkan ketersediaan unsur hara dalam medium tanam masih terbatas dan belum mampu mensuplai kebutuhan usur hara yang dibutuhkan tanaman untuk pertambahan lingkar batang bibit pinang. Ginting (2015) menyatakan bahwa untuk memperoleh efisiensi yang tinggi dari suatu pemupukan perlu diperhatikan beberapa faktor salah satunya adalah sifat dan ciri tanah.

Pemberian POC tandan kelapa pada berbagai dosis menunjukkan lingkar batang bibit pinang tidak berbeda nyata. Hal ini dikarenakan bahwa pada tanaman tahunan seperti tanaman pinang mengalami pertumbuhan yang lama ke arah horizontal sehingga untuk pertambahan lingkar batang pada tanaman pinang membutuhkan waktu relatif lama. Menurut Lizawati (2002), pada tanaman tahunan seperti tanaman perkebunan mengalami pertumbuhan yang lama ke arah horizontal, sehingga untuk pertumbuhan lingkar batang pada tanaman perkebunan membutuhkan waktu relatif lama.

\subsection{Luas Daun (cm)}

Hasil analisis sidik ragam menunjukan bahwa pemberian konsentrasi pupuk organik cair tandan kelapa tidak berpengaruh nyata terhadap luas daun bibit pinang di media gambut. Hasil uji lanjut dengan HSD pada taraf $5 \%$ dapat dilihat pada table dibawah ini;

Tabel 4 Pemanfaatan Pupuk Organik Cair Tandan Kelapa untuk pertumbuhan bibit pinang (Areca catechu L) di media gambut

\begin{tabular}{llc}
\hline Konsentrasi POC Tandan Kelapa & $\begin{array}{l}\text { Luas daun } \\
(\mathrm{cm})\end{array}$ \\
\hline $0 \mathrm{ml}$ konsentrasi POC tandan kelapa & $90,00 \mathrm{a}$ \\
$50 \mathrm{ml} / 500 \mathrm{ml}$ konsentrasi POC & $90,10 \mathrm{a}$ \\
tandan kelapa & & \\
$70 \mathrm{ml} / 500 \mathrm{ml}$ konsentrasi POC & $90,50 \mathrm{a}$ \\
$\begin{array}{l}\text { tandan kelapa } \\
90 \mathrm{ml} / 500 \mathrm{ml} \text { konsentrasi POC }\end{array}$ & $90,30 \mathrm{a}$
\end{tabular}

tandan kelapa

$110 \mathrm{ml} / 500 \mathrm{ml}$ konsentrasi POC 90,20 a tandan kelapa

Angka-angka yang di ikuti oleh huruf yang berbeda pada kolom yang sama menunjukan perbedaan yang nyata pada taraf terkecil $5 \%$ menurut uji HSD

Tabel 4 memperlihatkan bahwa pemberian POC tandan kelapa pada berbagai dosis menunjukkan luas daun terluas bibit pinang yang tidak berbeda nyata. Hal ini dikarenakan pemberian POC tandan kelapa belum menunjukkan adanya respon pertumbuhan tanaman terutama pada luas daun terluas bibit pinang, sehingga dapat dilihat bahwa antara pemberian dosis POC 0$110 \mathrm{ml}$ tidak berbeda nyata.

Hal ini dikarenakan kandungan unsur hara pada POC tandan kelapa masih belum cukup untuk penambahan luas daun, selain itu medium tanam yang digunakan dalam penelitian adalah jenis tanah gambut dimana tanah jenis ini memiliki kandungan unsur hara rendah dan $\mathrm{pH}$ masam yaitu 4,90-5,26 diduga unsur hara yang diberikan masih belum dapat tersedia dengan baik luas daun terluas bibit pinang relatif seragam. Menurut Hakim et al. (1986), bahwa ketersediaan unsur hara tanaman tidak terlepas dari kondisi tanah. Jika tanah tersebut mempunyai sifat fisik yang baik maka semakin tinggi porositas tanah dan daya tanah untuk memegang air juga semakin besar, keadaan ini menyebabkan ketersediaan air tercukupi, sehingga mendukung pertumbuhan bibit. Selain media tanaman diduga luas daun terluas pada bibit pinang berhubungan dengan jumlah daun, dimana pada Tabel 2 menunjukkan bahwa pertambahan jumlah daun bibit pinang berbeda tidak nyata, sehingga berpengaruh terhadap luas daun terluas pada bibit pinang. Jumlah daun berkaitan dengan proses fotosintesis, jumlah daun yang sedikit akan menghasilkan fotosintat yang sedikit sehingga fotosintat yang ditranslokasikan pada jaringan yang aktif seperti daun muda terbatas yang menyebabkan perkembangan luas daun tidak optimal

\subsection{Berat Kering Bibit ( $g$ )}

Hasil analisis sidik ragam menunjukan bahwa pemberian konsentrasi pupuk organik cair tandan kelapa berpengaruh nyata terhadap berat kering bibit pinang di media gambut. Hasil uji lanjut dengan HSD pada taraf 5\% dapat dilihat pada table dibawah ini;

Tabel 5 Pemanfaatan Pupuk Organik Cair Tandan Kelapa untuk pertumbuhan bibit pinang (Areca catechu L) di 
media gambut

\begin{tabular}{lcc}
\hline Konsentrasi POC Tandan Kelapa & $\begin{array}{l}\text { Berat kering } \\
\text { bibit (g) }\end{array}$ \\
\hline $\begin{array}{l}\mathrm{ml} \text { konsentrasi POC tandan } \\
17,79 \mathrm{c}\end{array}$ & $18,00 \mathrm{c}$ \\
$\begin{array}{l}\text { kelapa } \mathrm{ml} / 500 \mathrm{ml} \text { konsentrasi POC } \\
\text { tandan kelapa }\end{array}$ & $19,59 \mathrm{bc}$ \\
$70 \mathrm{ml} / 500 \mathrm{ml}$ konsentrasi POC & \\
$\begin{array}{l}\text { tandan kelapa } \\
90 \mathrm{ml} / 500 \mathrm{ml} \text { konsentrasi POC }\end{array}$ & $23,43 \mathrm{a}$ \\
tandan kelapa \\
$\begin{array}{l}110 \mathrm{ml} / 500 \mathrm{ml} \text { konsentrasi POC } \\
\text { tandan kelapa }\end{array}$ \\
$\begin{array}{l}\text { Angka-angka yang di ikuti oleh huruf yang berbeda pada } \\
\text { kolom yang sama menunjukan perbedaan yang nyata } \\
\text { pada taraf terkecil } 5 \% \text { menurut uji HSD }\end{array}$
\end{tabular}

Tabel 5 memperlihatkan bahwa pemberian POC tandan kelapa dengan konsentrasi 90 menujukkan berat kering bibit pinang yang tertinggi yaitu $23,43 \mathrm{~g}$ dan berbeda tidak nyata dengan pemberian konsentrasi $110 \mathrm{ml}$, namun berbeda nyata dengan perlakuan lainnya. Peningkatan berat kering tanaman dapat dilihat dari parameter tinggi bibit dan rasio tajuk akar yang memberikan hasil rerata tertinggi pada perlakuan yang sama yaitu pupuk POC kulit buah pisang dosis $90 \mathrm{ml} / 500 \mathrm{ml}$

Bahan kering tanaman mencerminkan status nutrisi suatu tanaman dan juga merupakan suatu indikator yang menentukan baik tidaknya suatu pertumbuhan dan perkembangan tanaman sehingga erat kaitanya dengan ketersediaan hara. Tanaman akan tumbuh subur jika ketersediaan unsur hara cukup dan dapat diserap oleh tanaman dengan baik. Menurut Dwijosepoetro (1996) berat kering tanaman mencerminkan status nutrisi tanaman karena berat kering tanaman tergantung pada jumlah, ukuran dan senyawa sel penyusun baik senyawa organik maupun senyawa anorganik. Berat kering merupakan ukuran pertumbuhan tanaman karena berat kering mencerminkan akumulasi senyawa organik yang berhasil disintesis oleh tanaman. Nyakpa et al. (1998) menyatakan bahwa tinggi rendahnya berat kering tanaman tergantung pada banyak atau sedikitnya serapan unsur hara yang berlangsung selama proses pertumbuhan tanaman tersebut.

\section{KESIMPULAN DAN SARAN}

1. Peningkatan dosis pupuk organik cair tandan kelapa meningkatkan pertambahan tinggi bibit, berat kering, dan tidak meningkatkan pertambahan jumlah daun, pertambahan lingkar batang dan luas daun terluas.
2. Pemberian pupuk organik cair kulit buah pisang dosis $90 \mathrm{ml}$ meningkatkan pertambahan tinggi bibit, berat kering bibit.

\section{DAFTAR PUSTAKA}

[1] M Agus, F., A. Mulyani, A. Dariah, Wahyunto, Maswar, and Erni Susanti. 2012. Peat maturity and thickness for carbon stock estimation. Proceedings, 14th International Peat Congress, 3-8 June 2012, Stockholm, Sweden.

[2] Badan Pusat Statistik. 2017. Produksi perkebunan rakyat berdasarkan jenis tanaman (ribu ton) 2012- 2015. http://www.bps.go.id. Diakses tanggal 27 juni 2018.

[3] Balai Penelitian Tanaman Palma. 2012. Prospek pengembangan pinang. http:// pustaka.litbang.pertanian.go.id/ publikasi.wr341124.pdf. tanggal 29 Maret 2018

[4] Bappenas. 2009. Reducing carbon Emission for Indonesian peatland. Interm Report of Multi diciplinary Study. Indonesian National Development PlanningBappenas Republic of Indonesia.

[5] Dalimartha, S. 2009. Atlas Tumbuhan Obat Indonesia. Jilid Keenam. Cetakan Pertama.Pustaka Bunda. Jakarta.

[6] Dwijosepoetro, D. 1996. Pengantar Fisiologi Tumbuhan. Gramedia. Jakarta.

[7] Gardner, F.P., R. B Pear dan F.L. Mitaheel. 1991. Fisiologi Tanaman Budidaya. Terjemahan Universitas Indonesia Press. Jakarta.

[8] Ginting, J. 2015. Pengaruh pemberian pupuk hayati cair dan pupuk NPK terhadap pertumbuhan bibit kelapa sawit di prenursery. Jurnal online Agroteknologi. 3 (3) : 1219- 1225.

[9] Hakim, N., Y.M. Nyakpa., A.M. Lubis., S.G. Nugroho., M.R. Saul., M.A. Diha., G.B. Hong dan H.H. Bailey. 1986. DasarDasar Ilmu Tanah. Penerbit UNILA. Lampung

[10] Harjadi, S.S. 2002. Pengantar Agronomi. Gramedia. Jakarta

[11] Kementrian Pertanian. 2013. Pinang Super dari Tanjung Jabung Barat. http://ditjenbun.pertanian.go.id/ tanhun/berita-187-pinangsuperdaritanjung-jabungbarat-.html. Diakses tanggal 28 Januari 2017

[12] Lakitan, B. 2010. Dasar-Dasar Fisiologi Tumbuhan. Raja Grafindo Persada. Jakarta. 
[13] Lingga, P. 1997. Petunjuk Penggunaan Pupuk. Penebar Swadaya. Jakarta.

[14] Lubis, A.U. 2008. Kelapa Sawit (Elaeis guineensis Jacq.) di Indonesia. Pusat Perkebunan Marihat. Pematang Siantar

[15] Lutony, T.L. dan Rahmayati, Y. 1994. Produksi dan Perdagangan Minyak Atsiri. Penebar Swadaya. Jakarta.

[16] Masganti. (2013). Teknologi inovatif pengelolaan lahan suboptimal gambut dan sulfat masam untuk peningkatan produksi tanaman pangan. Pengembangan Inovasi Pertanian 6(4):187-197.

[17] Miftahorrachman.dan T.A. Iqbal. 2009. Pengaruh Kematangan Buah dan Pengupasan Sabut Terhadap Kecepatan Kecambah, Daya Kecambah dan Vigor Bibit Pinang. Jurnal B Palma 36: 83-90.

[18] Najiyati, S., Lili Muslihat, dan I Nyoman N. Suryadiputra. (2005). Panduan pengelolaan lahan gambut untuk pertanian berkelanjutan. Proyek Climate Change, Forests and Peatlands in Indonesia. Wetlands International Indonesia Programme dan Wildlife Habitat Canada. Bogor. Indonesia

[19] Novizan. 2002. Petunjuk Pemupukan yang Efektif. Agromedia Pustaka. Jakarta

[20] Nyakpa, Y.M., A.M. Lubis, M.A. Pulung., A.G. Amrah., A. Munawar., G.B. Hong dan N. Hakim. 1998. Kesuburan Tanah. Universitas Lampung. Lampung.

[21] Pranata, A.S. 2004. Pupuk Organik Cair Aplikasi dan Manfaatnya. Agromedia Pustaka. Jakarta

[22] Sarisbury, F.B. dan C.W. Ross. 1995. Fisiologi Tumbuhan. Jilid 1. ITB. Bandung

[23] Satriadi, T. 2011. Kadar Tanin Tanaman Pinang (Areca catechu L.) Dari Pleihari.Jurnal Hutan Tropis. 12(32): 132-135.

[24] Sihombing, T. 2000. Pinang Budidaya dan Prospek Bisnis. Penebar Swadaya. Jakarta. 80 hal

[25] Syukur, C. dan Hernani. 2001. Budidaya Tanaman Obat Komersial. Penebar Swadaya. Jakarta

[26] Tim Sintesis Kebijakan. (2008). Pemanfaatan dan konservasi ekosistem lahan rawa gambut di Kalimantan. Pengembangan Inovasi Pertanian, 1(2), 149-156.

[27] Van Steenis, C.G.G.J. 2003.Flora. Alih Bahasa oleh Moeso Surjowinoto, Sunarto Hardjosuwarno, Soerjo Sodo Adisewojo, Wibisono, Margono
Partodidjojo, Sumantri Wirjahardja. PT. Pradnya Paramita. Jakarta. 131 hal 